in the centre. This frame is laid over the patient when in bed, and over it is placed a blanket or two, and these are tucked under the patient's chin. A tin tube is then passed into the hole at the bottom of the frame, and in the lower part of this tube a little spirit lamp is placed and lighted, and then the apparatus is complete. The air, heated by the lamp, passes up the tube, and is brought in contact with the surface of the body, which is generally restored to a natural and uniforin warmth with ar genial perspiration in about half an hour.

[This Lecture occupied an hour and a half in its delivery.]

Sir William Blizard, or Sir Villiam Wizard, as he is designated by the French Medical Journalists-maliciously enough, for the rogues know, as well as every body else, that the worthy lnight is no conjuror-sets his face against The Laverit regularly every Saturday morning.

Last week, when he came to that passage in the Adverisement, in which the College of Surgeons is characterized as a " benighted body," he exclaimed with great emotion, "Be-knighted body! Be-knighted body! I am a Knight, and I'll indict them for Scandalum Magnatum.

\section{THE REAL SIMON FURE.}

We have received a number of communications on the subject of the recent exploit of the consistent and conscientious person who unites the characters of a champion of "Hole and Corner" Surgery, and a humble transcriber of the pages of THE LaNCET. We insert the following letter with a view of enabling Mr. Tyrnen to judge of the feeling which his exploit has excited among those who are possessed of the volumes of Tie Lancer, and who have been-insuared into paying half a guinea for the twelve Lectures which the real Sinon PUR has nearly transcribed from our pages, not only without acknowledgment, but under the false pretence that his is the only correct and acthentic copy. One word as to the observation of our Correspondent respecting copyright. We know that we could expose the real Srion Pure in a court of justice; but we have alreadly declared that we think Sir A. Cooper's invalitable Lectures cannot be too extensively difiused, and it $\mathrm{BNNBOW}$, ashamed of being eclipsed by Mr. Tyrnell, were to imitate his example to-morrow, he may do $s 0$, as far as any legal interference on our part is concerned, with impunity. Unblushing as that indvidual's invasions of literary property have been, we do not think that even Bravodw, if he were to pirate our reports, would have the meanness to conceal the source from which he derived them, and the effrontery to represent himself as the author of them. A press of matter obliges us to postpone our dissection of the real Srmox $\mathrm{P}_{\mathrm{URB}}$ until next week. 
To the Editor of THE LANCET. Sin,-I think that you have been too lenient in your treatment, or rather notice, of what you have properly called " an act of literary dishonesty" on the part of the gentleman who has published Sir Astley Cooper's surgical lectures. From the very first, I have been a reader of your pages, as 1 conceived that they were a faithful transcript of the useful and scientific lectures given by SrR $A$. Cooper, nor have I been induced to change my opinion by reading the contents of a volume professing to cone from the pen of one of the surgeens of St. Thomas's Hospital. I will not enter upon the question, whether the publication of lectures (not his own) be consistent with the dignity and character of a hospital surgeon ? Mr. Tyraen has no doubt duly considered this question, and has probably been long held in suspense between his official dignity and, what you justly term, his cupidity: but where is the man over whom the "auri sacra fimes" will not at last prevail! In this instance, alas! it has induced him to become a literary pirate; to rob the pages of a work which he has, by every artifice in his power, endeavoured to put down, and to appropriate to himself the hardearned and faith ful reports of Tine Laxcer. The appearance of this volume explains the reason of his anxicty to suppress reports of lectures and hospital cases, and must fully satisfy the profession as to the worthiness of his motives. I have been in possession of $\mathrm{THE}$ LANCET from its very commencement, but I confess that I was induced to buy this new volume, expecting to find something more than TuE Lancer professed to give; my hopes were raised high by its pompous announcement; I looked for an edition of Sir Astuey's lectures, such as the world had never seen; and grievous has been my disappointment. $\mathrm{By}$ means of fine pape: and fine printing, he has given the rolume a some what novel appearance, but the contents are nothing but a reprint of the reports of THE LANCET, (embellished, I will not say, but) encumbered with the most paltry, uninforming, and useless cases of his own insertion, in the form of notes, such as 1 am convinced no monthir reriewer would have allowed a place in his journal ; they are at once an insult to the understanding of his readers, a disgrace to his professional character, and an evidence of his utter unfitness for the office he has assumed. I will not believe that Sir Astrey Cooper has given his sanction to this unpreceliented method of obtaining money from the hospital pupils. 'The surgeons of these institutions already extract enough from the pockets of their pupils, without having recourse to such unwarrantable modes of impoverishing them; their treatment of the young men who attend the hospitals you have often pointed out, and justly held up to the reprobation of the profession at large ; and it is to be expected that your appeals to their heads and hearts will not be without their due effect. Your next appeal should be to their pockets, their most sensitive point. The expense of this rolume is half-a-guinea, which will make the whole lectures, when complete, three guineas: while the whole series of The LANCET, including all Sr A Astrey's lectures, and a great variety of interesting E 2 
and instructive matter, has cost me only twenty-eight shillings. The bare-facedness of this job must be evident to the whole profession; it is to be viewed in no other light, than as an artifice to injure the sale of TuE LANCET, and to fill his own pocket. I $\mathrm{am}$, however, rather incredulous as to the former object being effected : it must take a much stronger head than, from the present specimen, I am inclined to give Mr.'TYRRELL credit for: his heart I believe to be strongly enlisted in the causeit is his head that rebels. It is a pity that the respectable name of Sir Astrey Cooper should have been lent to a transaction that will enhance neither the value of his lectures, nor increase his character for disinterestedness. His appearance in the business must, however, be attributed entirely to a deception; he cannot,before he compares the two, be aware of the identity between the volume in question and his lectures as published in THe La NCET. He has been the lupe of the mercenary rapaciousness of a young man, who, not possessing the necessary talents for publishing the lectures, has had recourse to the base expedient of purloining, from your valuable Numbers, that information which he wants the perseverance and ability to glean for himself. He may fill his coffers by such means, for literary repute surely cannot be one of his objects, but he will gain neither the good opinion of the wise, nor the esteem of the better part of his profession. I have always considered that you had the indirect sanction of Sir Astrey in publishing reports of his lectures; of this, however, you are the best judge, and also of your prior claim to a copyright in the work. Knowing that you have talents to defend yourself, and will not be sparing of the rod of castigation, where it is required, I wish you farewell, and success in your undertaking.

Your well-wisher and admirer.

\section{To the Editor of The Lancet.}

SI ,-Observing that you have occisionally devoted a part of your valuable publication to the correction of abuses in the Borough Hospitals, I take the liberty of submitting the following to your notice : It appears that, by a recent arrangement, the students of St. Thomas's are to procure subjects for themselves, during the ensuing season, and, that the new-comers, by the payment of a guinea, are entitled to the same privilege of dissecting; as those who entered perpetually last season, the latter of whom, notwithstanding the perpetuity of their free attendance, \&cc., are to pay the same full price for subjects as the former. Now this is undoubtedly unjust; for $\mathrm{Mr}$. Green cannot suppose that those students who entered last season should each have dissected ten guineas' worth of subjects; so that to many fellow-students with myself, in this predicament, there will be a clear loss of five guineas ; to some others, who have performed no dissections, a total loss. Yet Mr. G. complains of the balance being so very much against him. We entered with the understanding that subjects were to be procured for us at a certain fixed price, which they have been hitherto, and it is very unfair that that arrangement should now be altered. 
If these observations should be worthy your attention, the insertion of them will much oblige

Justitia Amicus.

\section{FOREIGN DEPARTMENT.}

ANALYSIS OF FOREIGN MEDICAL JOURNALS.

\section{REVUE MEDICALE.-AUGUST.}

Several interesting original communications are to be found in the work we have just named; and in the present Number we shall proceed to furnish our readers with the following :

\section{HYDROPHOBIA.}

Cases of Hydrophobia communicated, and followed with remarks. . By Professor RecaMIER.

First Case. On the $2 \%$ th of $\mathrm{Fe}-$ bruary, 1823, at seven o'clock in the morning, a man named Charles Mignot, a vine dresser, aged 24, of a bilious temperament, but of a spare habit, was attacked by a wolf. Mignot, being young, vigorous, and very courageous, thought fit to seize him by the tongue, in order to avoid being bitten, and with the design of suffocating him.

To do this, he thrust his right hand many times into the wolf's mouth, who made him pay dear for these imprudent and rash attempts. For the hand was not only bitten, but lacerated, mangled, and appeared as if pounded. The left hand was treated little better than the right, having been very deeply bitten in several places, especially about the thumb.

Besides the wounds which I have now cursorily described, $\mathrm{M} ; \mathrm{g}-$ not had received many bites on the upper and inner part of the left arm, which had passed through the part, as well as on the forearm of the same side. He had also seventeen deep wounds on the outer part of the right ham, and some on the lower and fore part of the left leg, which, on the twenty-third day from the accident, were freely suppurating.

Being afterwards called to this unfortunate, I was under the necessity of limiting myself to the mere dilatation of the wounds on the hand, and soaking them in warm water; from the impossibility of conveniently cauterising such a large number of wounds situated in the neighbourhood of joints and in tendinous parts, without exposing the patient to greater dangers, or perhaps to death itself, without being at the time satisfied that the animal was mad. On the third day, when I proposed to practise blood-letting, he told me that he had a profuse hæmorrhage from the nose, to which he was subject, which spared me the trouble. This hæinorrhage reappeared in the evening and in the following night, and has since taken place many times during the progress of the disease.

Emollient and narcotic fomentations, dressings of opiate cerate, and diluent drinks, with low diet, prevented the appearance of tetanic symptoms, which I had dreaded ; and every thing went on fa. vourably until the 1st of March, at which time the wounds of the left arm and hand had perfectly healed, when he was seized with a violent inflammation of the right hand, without any apparent cause, accompanied by considerabie swelling. 'The application of twelve leeches, followed by profuse bleed- 